\title{
Silicone elastomer map: design the ideal elastomer
}

\author{
Vaicekauskaite, Justina; Mazurek, Piotr; Vudayagiri, Sindhu; Skov, Anne Ladegaard
}

\section{Published in:}

Proceedings of SPIE

Link to article, DOI:

$10.1117 / 12.2515305$

Publication date:

2019

Document Version

Publisher's PDF, also known as Version of record

Link back to DTU Orbit

Citation (APA):

Vaicekauskaite, J., Mazurek, P., Vudayagiri, S., \& Skov, A. L. (2019). Silicone elastomer map: design the ideal elastomer. In Y. Bar-Cohen, \& I. A. Anderson (Eds.), Proceedings of SPIE: Electroactive Polymer Actuators and Devices (EAPAD) XXI (Vol. 10966). [1096625] SPIE - International Society for Optical Engineering. Proceedings of SPIE - The International Society for Optical Engineering https://doi.org/10.1117/12.2515305

\section{General rights}

Copyright and moral rights for the publications made accessible in the public portal are retained by the authors and/or other copyright owners and it is a condition of accessing publications that users recognise and abide by the legal requirements associated with these rights.

- Users may download and print one copy of any publication from the public portal for the purpose of private study or research.

- You may not further distribute the material or use it for any profit-making activity or commercial gain

- You may freely distribute the URL identifying the publication in the public portal 


\section{Silicone elastomer map: design the ideal elastomer}

Justina Vaicekauskaite, Piotr Mazurek, Sindhu Vudayagiri, Anne Ladegaard Skov

Justina Vaicekauskaite, Piotr Mazurek, Sindhu Vudayagiri, Anne Ladegaard Skov, "Silicone elastomer map: design the ideal elastomer," Proc. SPIE 10966, Electroactive Polymer Actuators and Devices (EAPAD) XXI, 1096625 (13 March 2019); doi: 10.1117/12.2515305

Event: SPIE Smart Structures + Nondestructive Evaluation, 2019, Denver, Colorado, United States 


\title{
Silicone elastomer map: Design the ideal elastomer
}

\author{
Justina Vaicekauskaite, Piotr Mazurek, Sindhu Vudayagiri, Anne Ladegaard Skov*
}

\author{
Technical University of Denmark, Danish Polymer Centre, Kgs. Lyngby 2800, DK \\ E-mail: al@kt.dtu.dk
}

\begin{abstract}
Soft, stretchable and light-weight transducers are most sought after for research on advanced applications like stretchable electronics, soft robotics and energy harvesters. Stretchable electronics require elastomers that have high elongation at break, high dielectric permittivity and high breakdown strength. Commercial silicone elastomer formulations often do not encompass all the necessary properties required to function effectively as stretchable transducers but they are used out of familiarity. In this study, most commonly used commercial silicone formulations are formulated with different stoichiometry and also blends of these formulations are made in order to manipulate their resulting properties. The properties of these blends like ultimate stress and strain, Young's modulus, dielectric permittivity and breakdown strength are investigated and mapped to identify those that have the best suited properties for fabricating soft stretchable devices. On a research level, Sylgard 184, Sylgard 186, Ecoflex 00-50, Ecoflex 00-30 and Ecoflex 00-10 are widely used for fabricating such soft devices and hence they will be worked upon in this study. The elastomers obtained using the methods of mixing illustrated here can act as a starting point for conceptualizing the feasibility of a product on research level.
\end{abstract}

\section{INTRODUCTION}

An unprecedented interest in transitioning from hard to soft machinery has propelled extensive research in the field of flexible and stretchable transducers [1][2]. Advantages of soft, stretchable, lightweight electronics that can withstand the wear and tear of movement in all degrees of freedom[3][4][5] are plenty compared to the conventional rigid technology. Particularly, for developing futuristic applications, for example: lifelike prosthetics and robots, intrinsic wearable biomedical devices, flexible digital computing devices, camouflage coatings and wave/solar/wind energy harvesters the aforementioned properties are key. Active research is taking place recently for developing robust and fully functional soft robotics[6], stretchable and soft electronics [7] wearable digital computing devices[7] flexible circuits and spatial solar panels [8], stretchable transparent conductors [9], printable elastic conductors[10], wearable, flexible devices for memories and computing[11], pressure sensitive sensor skin emulating human skin[12]-[19]. Such a myriad of applications requires a versatile elastomer that gives the best performance efficiency to these devices. Although, a variety of commercial formulations are available with superior mechanical properties in various grades they are not ideal for all the applications[20]. Lack of readily available elastomer formulations with customized properties for individual applications is one of the main constraining factors for producing stretchable devices with optimum performance efficiency. Although Sylgard 184 from Dow is very popular in research community for its versatile properties (low viscosity, high optical transmittance and durability[21], [22]), it has limited extensibility, high Young's modulus (Y) and moderate dielectric properties, which is a disadvantage for developing stretchable electronics, especially, high-voltage applications[23]. Sylgard 184 is used for a wide range of research activity, e.g. to develop shape memory composites[24], compliant graphite electrodes[25], microfluidic devices [26], super stretch strain sensor[27], micro contact pressure sensor [28] and tactile sensor[29].

An alternative to Sylgard 184 is a low-viscosity Ecoflex silicone elastomer kit by Smooth-On which is often considered too soft for many applications. Ecoflex is also being used for developing innovative applications in the form of soft matter sensor[30], capacitive strain sensor[31], strain sensors for prosthetics[32], hyper elastic pressure sensors[33], radio frequency sensors[34], sensors for wearable electronics[35], flexible ultrasonic imaging membranes [36], wearable

Electroactive Polymer Actuators and Devices (EAPAD) XXI, edited by Yoseph Bar-Cohen, lain A. Anderson, Proc. of SPIE Vol. 10966, 1096625 - @ 2019 SPIE · CCC code: 0277-786X/19/\$18 · doi: 10.1117/12.2515305 
pressure sensors based on piezo capacitance[37], wearable sensors for biomedical, healthcare[38], [39]. Though individually every formulation has a few remarkable properties, none of them have the ideal properties required to function as dielectric elastomer. Mechanical and electrical properties of these elastomers can be manipulated to a large degree either by changing the stoichiometry of the formulations or by blending two formulations with each other. A mixture of two formulations with contrasting properties, often results in a blend that is moderately reinforced with the properties of both formulations. Exploiting the synergy between two formulations with diverse properties is a proficient way to fabricate innovative silicone devices on research level. In the previous studies by Russo, S. et al. (2016)[40] and Park, S. et al. (2018)[41], the properties of the blends of some commercial formulations were investigated and it was concluded that by blending Dragon Skin with Sylgard 184, the extensibility and tear resistance of Sylgard 184 was considerably improved while retaining its capacity to plasma bond.

In the current work, popular commercial silicone formulations (Sylgard 184, Sylgard 186 and Ecoflex 00-50, Ecoflex 0030, Ecoflex 00-10) are mixed at different stoichiometric ratios and are also blended with each other in order to tweak their properties. The formulations and blends are investigated to find the best suited formulation for elastomeric transducers. Optically transparent formulations are chosen for our study as they are sought after for many applications [9][42] especially for wearable invisible sensors. Ecoflex silicones are chosen because of their low viscosity and low Young's modulus. Furthermore, the properties of the blends and mixtures are mapped to guide the silicone research community to pick and choose a formulation that best suits the intended application.

\section{EXPERIMENTAL}

\subsection{Materials}

Five different two-part (A and B) commercial silicone elastomers were used. Sylgard 184 and 186 silicone elastomers were provided by Dow, Germany. Silicone rubbers Ecoflex 00-50, 00-30 and 00-10 were provided by FormX, Netherlands.

\subsection{Sample preparation}

Sample compositions are shown in Table 1. Parts A and B of every silicone formulation were weighed according to the mixing ratio and mixed in a SpeedMixer DAC 150 FVZ-K for 2 minutes at $2000 \mathrm{rpm}$. No additional degassing step is required while using a speed mixer. The manufacturer recommended mixing ratios of Sylgard 184 and 186 of 10:1 (part A: part B) and for Ecoflex 00-50, 00-30 and 00-10 the mixing ratio is 1:1 (part A: part B). Depending on the experiment type, mixed compositions were processed in different ways. All measurements were carried out at room temperature and room humidity. No solvent or flow control agent was used.

To make films, formulations were doctor bladed on acetate/polyester support film, provided by Pütz GmbH + Co. Folien

KG, Germany. Blade gap was $400 \mu \mathrm{m}$ and $200 \mu \mathrm{m}$, respectively. All formulations were cured at $80{ }^{\circ} \mathrm{C}$ for 2 hours. After curing, film thicknesses were $300 \mu \mathrm{m} \pm 10 \%$ and $100 \mu \mathrm{m} \pm 20 \%$, respectively as the film thicknesses usually vary from the blade thickness [20]. $1 \mathrm{~mm} \pm 20 \%$ thick samples were prepared in a metal mold and $6.4 \mathrm{~mm}$ or thicker samples were prepared in a metal cup, both type of samples were cured at $80^{\circ} \mathrm{C}$ for 2 hours.

\subsection{Mechanical properties}

Stress-strain measurements were carried out with Instron 3345 tensile tester equipped with a $500 \mathrm{~N}$ load cell. The effective samples dimensions were $5 \mathrm{~cm} \times 2 \mathrm{~cm} \times 300 \mu \mathrm{m}$. The applied crosshead velocity was $5 \mathrm{~cm} / \mathrm{min}$.

\subsection{Breakdown strength}

Breakdown tests were performed on an in-house-built instrument following the international standards (IEC 60243-1 (1998) and IEC 60243-2 (2001)) [43]. $100 \mu \mathrm{m} \pm 20 \%$ thick film samples were placed on a plastic support during breakdown testing. The plastic frames with silicone film were placed into the breakdown instrument between two semispherical electrodes made of stainless steel. Subsequently, $100 \mathrm{~V} / \mathrm{s}$ voltage ramp was applied until polymer film broke down. Breakdown strengths were calculated from Weibull analysis[44]. 


\subsection{Dielectric permittivity}

Novocontrol Broadband Dielectric Spectrometer, Germany was used to investigate dielectric properties. Disc samples (1 $\mathrm{mm} \pm 20 \%$ thick, $25 \mathrm{~mm}$ diameter) were placed between two gold electrodes. Samples were tested at room temperature in the frequency range from $10^{-1}$ to $10^{6} \mathrm{~Hz}$ at $1 \mathrm{~V}$.

Table 1: Sample list with corresponding sample names and mixing ratios.

\begin{tabular}{|c|c|c|c|c|c|}
\hline No. & Sample name & Part I ${ }^{a}$ & $\begin{array}{c}\text { Part I by } \\
\text { weight }\end{array}$ & Part II $^{\text {a }}$ & $\begin{array}{c}\text { Part II by } \\
\text { weight }\end{array}$ \\
\hline 1. & Sylgard 184 5:1 & Sylgard 184 (5:1) & - & - & - \\
\hline 2. & Sylgard 184 10:1 & Sylgard 184 (10:1) & - & - & - \\
\hline 3. & Sylgard 184 15:1 & Sylgard $184(15: 1)$ & - & - & - \\
\hline 4. & Sylgard 184 20:1 & Sylgard $184(20: 1)$ & - & - & - \\
\hline 5. & Sylgard 186 5:1 & Sylgard 186 (5:1) & - & - & - \\
\hline 6. & Sylgard 186 10:1 & Sylgard 186 (10:1) & - & - & - \\
\hline 7. & Sylgard MIX 1:3 & Sylgard 184 (10:1) & 1 & Sylgard $186(10: 1)$ & 3 \\
\hline 8. & Sylgard MIX 1:1 & Sylgard 184 (10:1) & 1 & Sylgard $186(10: 1)$ & 1 \\
\hline 9. & Sylgard MIX 3:1 & Sylgard 184 (10:1) & 3 & Sylgard 186 (10:1) & 1 \\
\hline 10. & Ecoflex 00-50 & Ecoflex 00-50 & - & - & - \\
\hline 11. & Eco MIX 00-50 1:3 & Sylgard $184(10: 1)$ & 1 & Ecoflex 00-50 & 3 \\
\hline 12. & Eco MIX 00-50 1:1 & Sylgard 184 (10:1) & 1 & Ecoflex 00-50 & 1 \\
\hline 13. & Eco MIX 00-50 3:1 & Sylgard $184(10: 1)$ & 3 & Ecoflex 00-50 & 1 \\
\hline 14. & Ecoflex 00-30 & Ecoflex 00-30 & - & - & - \\
\hline 15. & Eco MIX 00-30 1:3 & Sylgard 184 (10:1) & 1 & Ecoflex 00-30 & 3 \\
\hline 16. & Eco MIX 00-30 1:1 & Sylgard $184(10: 1)$ & 1 & Ecoflex 00-30 & 1 \\
\hline 17. & Eco MIX 00-30 3:1 & Sylgard 184 (10:1) & 3 & Ecoflex 00-30 & 1 \\
\hline 18. & Ecoflex 00-10 & Ecoflex 00-10 & - & - & - \\
\hline 19. & Eco MIX 00-10 1:3 & Sylgard $184(10: 1)$ & 1 & Ecoflex 00-10 & 3 \\
\hline 20. & Eco MIX 00-10 1:1 & Sylgard 184 (10:1) & 1 & Ecoflex 00-10 & 1 \\
\hline 21. & Eco MIX 00-10 3:1 & Sylgard $184(10: 1)$ & 3 & Ecoflex 00-10 & 1 \\
\hline
\end{tabular}

${ }^{a}$ Mixing weight ratio of part A and part B (A:B) of the silicone kits in brackets

\section{RESULTS and DISCUSSION}

The ultimate stress $\left(\sigma_{\max }(\mathrm{MPa})\right)$, elongation at break $\left(\varepsilon_{\text {tensile }}(\%)\right)$, and breakdown strength $\left(\mathrm{E}_{\mathrm{BD}}(\mathrm{V} / \mu \mathrm{m})\right)$ of all the formulations are plotted with their respective Y (MPa) in Figure 1. All the properties are also tabulated (see Table 1). The figure of merit for a dielectric elastomer actuator $\left(\mathrm{F}_{\mathrm{om}}(\mathrm{DEA})\right)$ and the figure of merit for a dielectric elastomer generator $\left(\mathrm{F}_{\mathrm{om}(\mathrm{DEG})}\right)$ are calculated and plotted in Figure 2. The properties of formulations which are relevant for stretchable electronics are discussed further below.

\subsection{Mechanical properties/elasticity}

The ultimate tensile strengths of all formulations are plotted with their respective Y in Figure 1 (a). For soft and stretchable devices, extensibility (Figure 1b) is a parameter of utmost importance[45]. Of all the formulations, Sylgard 184 has the least extensibility. By varying the mixing ratio of Sylgard 184 (Part A: Part B $=20: 1$ ) the extensibility is doubled (135\% to $296 \%$ ). SylgardMIX (1:3) shows improved extensibility (135\% to 365\%) over Sylgard 184. Though, Ecoflex 00-50, Ecoflex $^{\mathrm{TM}}$ 00-30 have the highest extensibility of $~ 800 \%$ their blends with Sylgard 184 (Eco MIX 00-50 and Eco MIX 0030 ) show a rather limited extensibility of up to only $\sim 360 \%$. The addition of a soft formulation to a hard one results in intermediate properties, as expected. The properties of the formulations indicate that blending is a quick and a surefire approach to make reliable soft networks with mechanical integrity as opposed to varying the stoichiometry, which, if done inappropriately, often leads to formation of weak networks [20]. 


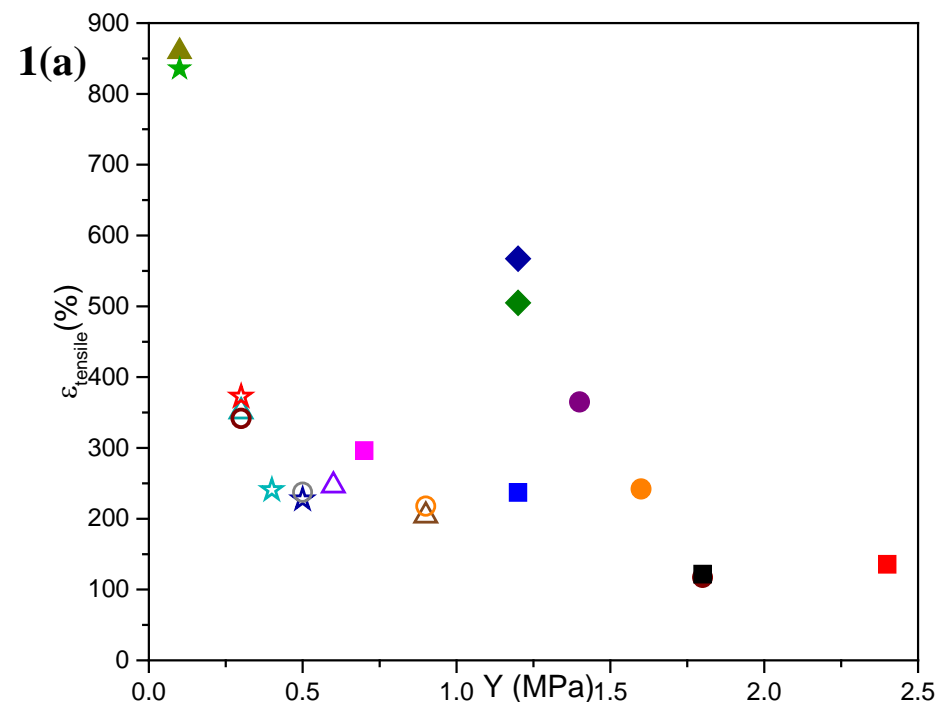

\section{Legend}

1(b)

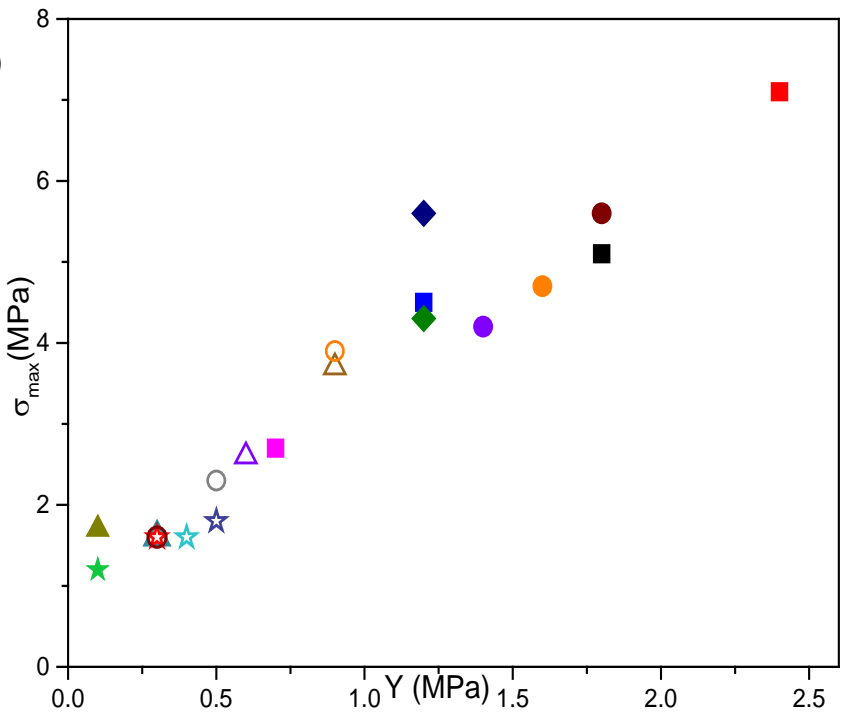

Sylgard 184 5:1

Sylgard 184 10:1

Sylgard 184 15:1

Sylgard 184 20:1

Sylgard 186 5:1

Sylgard 186 10:1

Sylgard MIX 1:3

Sylgard MIX 1:1

Sylgard MIX 3:1

Ecoflex 00-50

$\triangle$ Eco MIX 00-50 1:3

$\triangle$ Eco MIX 00-50 1:1

$\triangle$ Eco MIX 00-50 3:1

$\star$ Ecoflex 00-30

« Eco MIX 00-30 1:3

ts Eco MIX 00-30 1:1

¿ Eco MIX 00-30 3:1

O Eco MIX 00-10 1:3

O Eco MIX 00-10 1:1

O Eco MIX 00-10 3:1

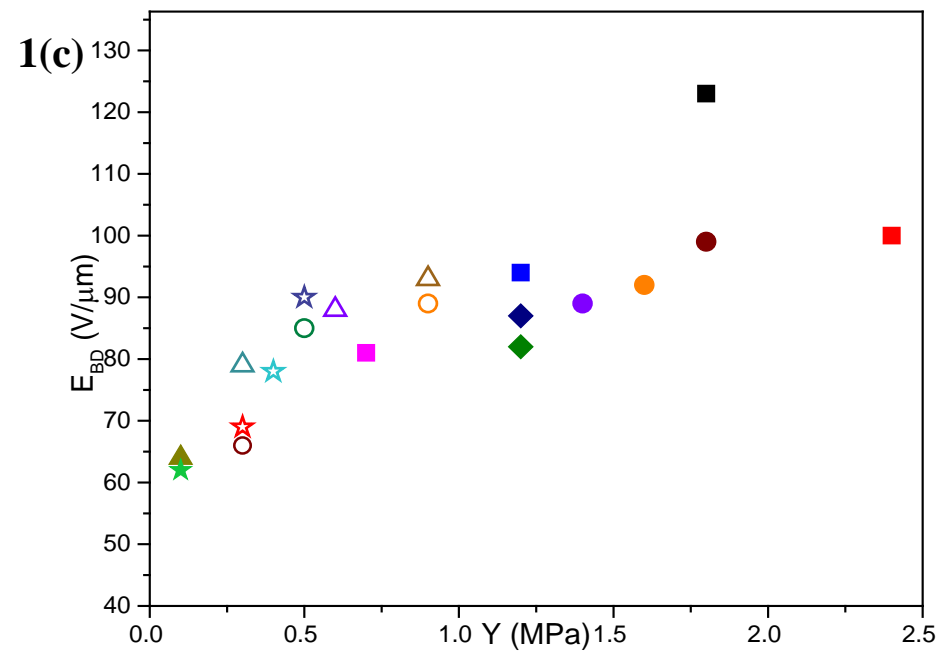

Figure 1: Various properties of investigated silicone elastomers plotted against the Young's modulus (Y). a) Ultimate stress Vs Y, b) Tensile strain vs. Y, c) Electrical breakdown vs. Y. 


\subsection{Electrical properties}

When Sylgard 184 is mixed in the ratio of 5:1, the breakdown strength is improved from 100 to $123 \mathrm{~V} / \mu \mathrm{m}$ (Figure 1(c)) compared to Sylgard 184 mixed in the ratio of 10:1. When Sylgard 186 is mixed in the ratio of 5:1, the dielectric permittivity improves from 2.8 to 3.2 compared to Sylgard 186 mixed in the ratio of 10:1. The blends resulting from the amalgamation of formulations with diverse properties, i.e. Eco MIX 00-50, Eco MIX 00-30, Eco MIX 00-10 benefit from being moderately reinforced by the high dielectric permittivity of Ecoflex ${ }^{\mathrm{TM}}$ and high breakdown strength of Sylgard 184. Compared to Sylgard 184; Eco MIX 00-50, Eco MIX 00-30 and Eco MIX 00-10 show improved dielectric permittivity and a slightly degraded breakdown strength. Researchers, can quickly and efficiently introduce better dielectric permittivity and breakdown strength into silicone formulations by fabricating such blends instead of using high dielectric constant fillers (e.g. titanium dioxide) which require tedious processing[46][47]. Furthermore, it was observed that all the investigated elastomers broke down electrically in similar ways by creating silica as a solid residual [48][49].

\subsection{Figure of Merit}

The $\mathrm{F}_{\mathrm{om}}(\mathrm{DEA})[50]$ and $\mathrm{F}_{\mathrm{om}}(\mathrm{DEG})[51]$ are designed to facilitate an easy evaluation of the performance of the elastomers as dielectric elastomer transducers. Mathematically, $F_{\text {om }}(\mathrm{DEA})$ and $\mathrm{F}_{\mathrm{om}}(\mathrm{DEG})$ are expressed as shown in equation(2) and equation(3).

$F_{o m}(D E A)=\frac{3 \varepsilon^{\prime} \varepsilon_{O} E_{B D}^{2}}{Y}$

$F_{o m}(D E G)=\frac{\varepsilon^{\prime} \varepsilon_{o} E_{B D}^{2}}{2 \varphi}$

Table 2: Properties of the different silicone formulations

\begin{tabular}{|c|c|c|c|c|c|}
\hline$-x_{2}$ & \multicolumn{3}{|c|}{ Mechanical properties } & \multicolumn{2}{|c|}{ Dielectric properties } \\
\hline Sample name & Y [MPa] & Etensile [\%] & $\sigma_{\max }[\mathrm{MPa}]$ & $\varepsilon^{\prime}(1 \mathrm{~Hz})$ & $\mathrm{E}_{\mathrm{BD}}[\mathrm{V} / \mu \mathrm{m}]$ \\
\hline Sylgard 184 5:1 & 1,8 & 121,8 & 5,1 & 2,9 & 123 \\
\hline Sylgard 184 10:1 & 2,4 & 135,6 & 7,1 & 3,0 & 100 \\
\hline Sylgard 184 15:1 & 1,2 & 237,0 & 4,5 & 3,0 & 94 \\
\hline Sylgard 184 20:1 & 0,7 & 296,3 & 2,7 & 3,1 & 81 \\
\hline Sylgard 186 5:1 & 1,2 & 504,9 & 4,3 & 3,2 & 82 \\
\hline Sylgard 186 10:1 & 1,2 & 567,2 & 5,6 & 2,8 & 87 \\
\hline Sylgard MIX 1:3 & 1,4 & 365,0 & 4,2 & 2,8 & 89 \\
\hline Sylgard MIX 1:1 & 1,6 & 242,1 & 4,7 & 3,0 & 92 \\
\hline Sylgard MIX 3:1 & 1,8 & 117,1 & 5,6 & 3,2 & 99 \\
\hline Ecoflex ${ }^{\mathrm{TM}}$ 00-50 & 0,1 & 859,7 & 1,7 & 3,4 & 64 \\
\hline Eco MIX 00-50 1:3 & 0,3 & 351,4 & 1,6 & 3,3 & 79 \\
\hline Eco MIX 00-50 1:1 & 0,6 & 246,8 & 2,6 & 3,1 & 88 \\
\hline Eco MIX 00-50 3:1 & 0,9 & 204,4 & 3,7 & 3,1 & 93 \\
\hline Ecoflex ${ }^{\text {TM }}$ 00-30 & 0,1 & 835,4 & 1,2 & 3,8 & 62 \\
\hline Eco MIX 00-30 1:3 & 0,3 & 372,6 & 1,6 & 3,2 & 69 \\
\hline Eco MIX 00-30 1:1 & 0,4 & 240,7 & 1,6 & 3,6 & 78 \\
\hline Eco MIX 00-30 3:1 & 0,5 & 227,6 & 1,8 & 3,2 & 90 \\
\hline Ecoflex ${ }^{\mathrm{TM}}$ 00-10 & - & - & - & - & 38 \\
\hline Eсо MIX 00-10 1:3 & 0,3 & 341,6 & 1,6 & 4,0 & 66 \\
\hline Eco MIX 00-10 1:1 & 0,5 & 237,5 & 2,3 & 3,5 & 85 \\
\hline Eco MIX 00-10 3:1 & 0,9 & 217,9 & 3,9 & 3,4 & 89 \\
\hline
\end{tabular}


Here, $E_{\mathrm{BD}}$ is the electrical field at which electrical breakdown occurs and $\varphi$ is the strain energy function of the elastomer, $\varepsilon_{0}$ is the permittivity of free space $\left(8.854 \times 10^{-12} \mathrm{~F} \cdot \mathrm{m}^{-1}\right)$ and $\varepsilon$ ' is the relative permittivity of our formulations. $\mathrm{F}_{\mathrm{om}}(\mathrm{DEG})$ is comprehensive only when the strain energy function of the elastomer is considered. The strain energy density $(\varphi)$ for our elastomers is calculated from their hysteresis curves[52] in the reverse extension cycle (15\% to 0\%strain) where the displacement is within the linear stress strain regime. Based on the $\mathrm{F}_{\text {om, }}$ (Figure 2(a) and 2(b)), Eco MIX 00-50 (1:3), Ecoflex 00-30, Eco MIX 00-10 (1:1) are the best formulations to function as stretchable transducers/electronics and by far exceed the benchmark Sylgard 184. In fact, all the formulations demonstrate an equal or better $F_{\text {om }}(D E A)$ and $F_{\text {om }}(D E G)$ than the rigid Sylgard 184. Although, $F_{o m}(D E A)$ and $F_{o m}(D E G)$ have a strong dependency on the breakdown strength of the formulations, the influence of $\mathrm{Y}$ and $\varphi$ cannot be undermined as is evident from our calculations. Another issue to consider when transitioning from research to commercialization is the life-time. Research within this crucial topic is emerging and holds great promise for the DEG technology[53]-[58].
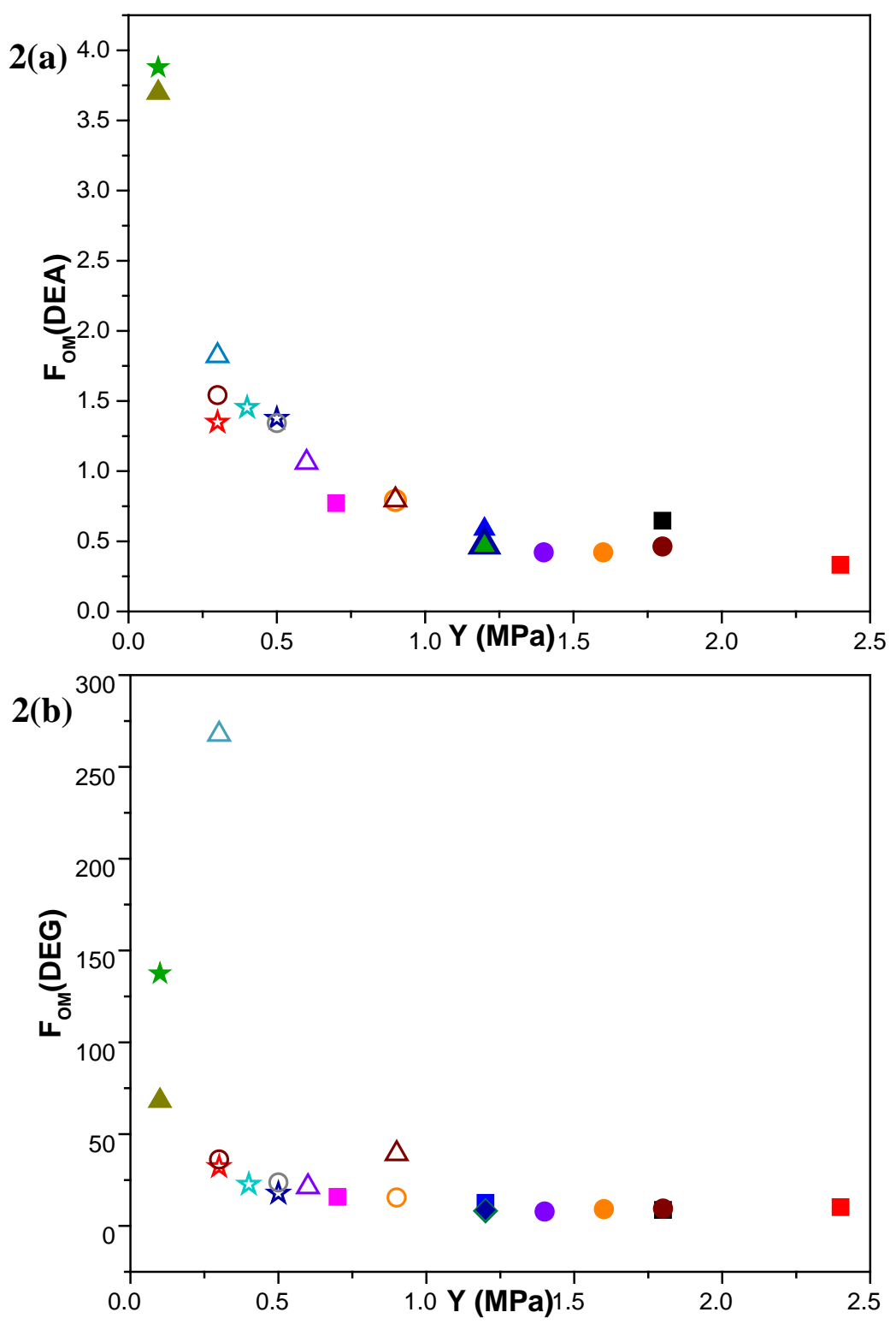

\section{Legend}

- Sylgard 184 5:1

- Sylgard 184 10:1

- Sylgard 184 15:1

Sylgard 184 20:1

Sylgard 186 5:1

Sylgard 186 10:1

Sylgard MIX 1:3

Sylgard MIX 1:1

Sylgard MIX 3:1

Ecoflex 00-50

Eco MIX 00-50 1:3

Eco MIX 00-50 1:1

Eco MIX 00-50 3:1

Ecoflex 00-30

¿ Eco MIX 00-30 1:3

文 Eco MIX 00-30 1:1

¿ Eco MIX 00-30 3:1

O Eco MIX 00-10 1:3

Eco MIX 00-10 1:1

O Eco MIX 00-10 3:1

Figure 2: Figure of merit for an actuator ( $\mathrm{F}_{\mathrm{om}}(\mathrm{DEA})(\mathrm{a})$ ) and a generator ( $\left.\mathrm{F}_{\mathrm{om}}(\mathrm{DEG})(\mathrm{b})\right)$. For the calculations $\varepsilon$ ' measured at $1 \mathrm{~Hz}$ and $\varphi$ measured from $15 \%$ to $1 \%$ strain were used. 


\section{CONCLUSIONS}

We formulate 21 different recipes by combining some commonly used commercial silicone formulations (Sylgard 186, Sylgard 184 and Ecoflex 00-50, 00-30 and 00-10) at different stoichiometric ratios and also by blending two different formulations with each other. By doing so, we establish that the properties can be manipulated suitably. Furthermore, the electrical and mechanical properties of these blends are investigated and mapped with an objective to find those that are suitable for the fabrication of soft and stretchable transducers. The electrical and mechanical properties of the formulations are mapped and their figure of merit is also calculated. By combining Ecoflex 00-50 and Sylgard 184, a highly extensible elastomer blend with optimum dielectric permittivity and breakdown strength is obtained which qualifies as a good candidate for fabricating transducers based on the figure of merit. This synergy of two formulations with different properties can act to our advantage by providing a blend that is suitably reinforced with desired properties. These formulations can act as a good starting point for developing advanced hi-tech, versatile and stretchable devices.

\section{REFERENCES}

[1] S. Bauer, S. Bauer-Gogonea, I. Graz, M. Kaltenbrunner, C. Keplinger, and R. Schwödiauer, "25th anniversary article: A soft future: From robots and sensor skin to energy harvesters,” Adv. Mater., vol. 26, no. 1, pp. 149162, 2014.

[2] R. Herbert, J. Kim, Y. S. Kim, H. M. Lee, and W. Yeo, "Soft Material-Enabled, Flexible hybrid Electronics for Medicine, Healthcare, and Human-Machine Interfaces,” Materials (Basel)., vol. 11, no. 187, pp. 1-33, 2018.

[3] J. D. Madden, "Mobile Robots : Motor Challenges and Materials Solutions," Science, vol. 318, pp. 1094-1098, 2007.

[4] I. A. Anderson, T. A. Gisby, T. G. Mckay, B. M. O. Brien, E. P. Calius, and E. P. Calius, "Multi-functional dielectric elastomer artificial muscles for soft and smart machines,” J. Appl. Phys., vol. 112, no. 041101, 2012.

[5] Z. Huang, Y. Hao, Y. Li, H. Hu, C. Wang, A. Nomoto, T. Pan, Y. Gu, Y. Chen, T. Zhang, W. Li, Y. Lei, N. Kim, C. Wang, L. Zhang, J. W. Ward, A. Maralani, X. Li, M. F. Durstock, A. Pisano, Y. Lin, and S. Xu, "Threedimensional integrated stretchable electronics," Nat. Electron., vol. 1, no. 8, pp. 473-480, 2018.

[6] D. Rus and M. T. Tolley, "Design, fabrication and control of soft robots," Nature, vol. 521, no. 7553, pp. 467475, 2015.

[7] D. D. Michael, "Stretchable and Soft Electronics using Liquid Metals,” Adv. Mater., vol. 1606425, no. 29, pp. 119, 2017.

[8] I. M. Graz, D. P. J. Cotton, and S. P. Lacour, "Extended cyclic uniaxial loading of stretchable gold thin-films on elastomeric substrates," Appl. Phys. Lett., vol. 94, no. 7, 2009.

[9] C. Keplinger, J.-Y. Sun, C. C. Foo, P. Rothemund, G. M. Whitesides, and Z. Suo, "Stretchable, transparent, ionic conductors,” Science, vol. 341, no. 6149, pp. 984-987, 2013.

[10] N. Matsuhisa, M. Kaltenbrunner, T. Yokota, H. Jinno, K. Kuribara, T. Sekitani, and T. Someya, "Printable elastic conductors with a high conductivity for electronic textile applications,” Nat. Commun., vol. 6, no. May, 2015.

[11] K. Rajan, E. Garofalo, and A. Chiolerio, “Devices for Memories and Computing,” Sensors, vol. 18, no. 367, pp. 1-16, 2018.

[12] S. Park, H. Kim, M. Vosgueritchian, S. Cheon, H. Kim, J. H. Koo, T. R. Kim, S. Lee, G. Schwartz, H. Chang, and Z. Bao, "Stretchable energy-harvesting tactile electronic skin capable of differentiating multiple mechanical stimuli modes," Adv. Mater., vol. 26, no. 43, pp. 7324-7332, 2014.

[13] X. Wang, Y. Gu, Z. Xiong, Z. Cui, and T. Zhang, "Silk-Molded Flexible, Ultrasensitive, and Highly Stable Electronic Skin for Monitoring Human Physiological Signals,” Adv. Mater., vol. 26, pp. 1336-1342, 2014.

[14] C. Choong, M. Shim, B. Lee, S. Jeon, D. Ko, T. Kang, J. Bae, S. H. Lee, K. Byun, J. Im, Y. J. Jeong, C. E. Park, J. Park, and U. Chung, "Highly Stretchable Resistive Pressure Sensors Using a Conductive Elastomeric Composite on a Micropyramid Array,” Adv. Mater., vol. 26, pp. 3451-3458, 2014.

[15] S. C. B. Mannsfeld, B. C. Tee, R. M. Stoltenberg, C. V. H. Chen, S. Barman, B. V. O. Muir, A. N. Sokolov, C. Reese, and Z. Bao, "Highly sensitive flexible pressure sensors with microstructured rubber dielectric layers," Nat. Mater., vol. 9, no. 10, pp. 859-864, 2010.

[16] S. Jung, J. H. Kim, J. Kim, S. Choi, J. Lee, I. Park, T. Hyeon, and D. Kim, "Reverse-Micelle-Induced Porous Pressure-Sensitive Rubber for Wearable Human - Machine Interfaces,” Adv. Mater., vol. 26, pp. 4825-4830, 
2014.

[17] L. Pan, A. Chortos, G. Yu, Y. Wang, S. Isaacson, R. Allen, Y. Shi, R. Dauskardt, and Z. Bao, “An ultra-sensitive resistive pressure sensor based on hollow-sphere microstructure induced elasticity in conducting polymer film," Nat. Commun., vol. 5, pp. 1-8, 2014.

[18] L. Viry, A. Levi, M. Totaro, A. Mondini, V. Mattoli, B. Mazzolai, and L. Beccai, "Flexible Three-Axial Force Sensor for Soft and Highly Sensitive Artificial Touch,” Adv. Mater., vol. 26, pp. 2659-2664, 2014.

[19] B. Su, S. Gong, Z. Ma, L. W. Yap, and W. Cheng, "Mimosa-Inspired Design of a Flexible Pressure Sensor with Touch Sensitivity,” Adv. Mater., vol. 11, no. 16, pp. 1886-1891, 2015.

[20] P. Mazurek, S. Vudayagiri, and A. L. Skov, "How to tailor flexible silicone elastomers with mechanical integrity: a tutorial review,” R. Soc. Chem., pp. 1-18, 2019.

[21] P. Mazurek, S. Hvilsted, and A. L. Skov, "Green silicone elastomer obtained from a counterintuitively stable mixture of glycerol and PDMS,” Polymer (Guildf)., vol. 87, pp. 1-7, 2016.

[22] P. Mazurek, M. A. Brook, and A. L. Skov, "Glycerol-Silicone Elastomers as Active Matrices with Controllable Release Profiles,” Langmuir, vol. 34, pp. 11559-11566, 2018.

[23] P. Mazurek, L. Yu, R. Gerhard, W. Wirges, and A. L. Skov, “Glycerol as high-permittivity liquid filler in dielectric silicone elastomers,” J. Appl. Polym. Sci., vol. 133, pp. 1-8, 2016.

[24] X. Luo and P. T. Mather, "Preparation and Characterization of Shape Memory Elastomeric Composites," Macromolecules, vol. 42, no. 19, pp. 7251-7253, 2009.

[25] M. Kujawski, J. D. Pearse, and E. Smela, "Elastomers filled with exfoliated graphite as compliant electrodes,” Carbon N. Y., vol. 48, no. 9, pp. 2409-2417, 2010.

[26] I. D. Johnston, D. K. McCluskey, C. K. L. Tan, and M. C. Tracey, "Mechanical characterization of bulk Sylgard 184 for microfluidics and microengineering,” J. Micromech. Microeng., vol. 24, p. 035017, 2014.

[27] L. Cai, L. Song, P. Luan, Q. Zhang, N. Zhang, Q. Gao, and D. Zhao, "Super-stretchable, Transparent Carbon,” Sci. Rep., vol. 3, no. 3048, pp. 1-9, 2013.

[28] S. Woo, J. Kong, D. Kim, and J. Kim, “A thin all-elastomeric capacitive pressure sensor array based on microcontact printed elastic conductors,” J. Mater. Chem. C, vol. 2, pp. 4415-4422, 2014.

[29] H. Lee, S. Chang, and E. Yoon, “A Flexible Polymer Tactile Sensor : Fabrication and Modular Expandability for Large Area Deployment,” J. Microelectromechanical Syst., vol. 15, no. 6, pp. 1681-1686, 2006.

[30] R. Rocha, P. Lopes, A. T. De Almeida, and M. Tavakoli, "Soft-matter sensor for proximity , tactile and pressure detection,” in International Conference on Intelligent Robots and Systems, 2017, pp. 3734-3738.

[31] T. Houghton, J. Vanjaria, T. Murphy, and H. Yu, "Stretchable Capacitive Strain Sensors Based on a Novel Polymer Composite Blend,” 2017 IEEE 67th Electron. Components Technol. Conf., vol. 1, pp. $2263-2268,2017$.

[32] S. Kumbay-yildiz, "Fabrication and characterisation of highly stretchable elastomeric strain sensors for prosthetic hand applications,” Sensors and Actuators A:Physical, vol. 247, pp. 514-521, 2016.

[33] Y. Park, C. Majidi, R. Kramer, B. Phillipe, and R. J. Wood, "Hyperelastic pressure sensing with a liquidembedded elastomer,” J. Micromechanics Microengineering, vol. 20, no. 125029, pp. 1-6, 2010.

[34] E. Seunghyun and L. Sungjoon, "Stretchable Complementary Split Ring Resonator (CSRR)-Based Radio Frequency (RF) Sensor for Strain Direction and Level Detection,” Sensors, vol. 16, no. 1667, pp. 1-12, 2016.

[35] B. W. An, J. H. Shin, S. Kim, J. Kim, S. Ji, J. Park, Y. Lee, J. Jang, Y. Park, E. Cho, S. Jo, and J. Park, “Smart Sensor Systems for Wearable Electronic Devices,” Polymers (Basel)., vol. 9, no. 303, pp. 1-41, 2017.

[36] H. Hu, X. Zhu, C. Wang, L. Zhang, X. Li, S. Lee, Z. Huang, R. Chen, Z. Chen, C. Wang, Y. Gu, Y. Chen, Y. Lei, T. Zhang, N. Kim, Y. Guo, Y. Teng, W. Zhou, Y. Li, A. Nomoto, S. Sternini, Q. Zhou, M. Pharr, F. Lanza, and $\mathrm{S}$. $\mathrm{Xu}$, “Stretchable ultrasonic transducer arrays for three-dimensional imaging on complex surfaces," Sci. Adv., vol. 4, no. March, pp. 1-12, 2018.

[37] D. Kwon, T. Lee, J. Shim, S. Ryu, M. S. Kim, S. Kim, T. Kim, and I. Park, "Highly Sensitive, Flexible, and Wearable Pressure Sensor Based on a Giant Piezocapacitive Effect of Three-Dimensional Microporous Elastomeric Dielectric Layer,” ACS Appl. Mater. Interfaces, vol. 8, pp. 16922-16931, 2016.

[38] S. Yao, P. Swetha, and Y. Zhu, "Nanomaterial-Enabled Wearable Sensors for Healthcare,” Adv. Healthc. Mater., vol. 7, no. 1700889, pp. 1-27, 2018.

[39] Kenry, J. C. Yeo, and C. T. Lim, "Emerging fl exible and wearable physical sensing platforms for healthcare and biomedical applications,” Microsystems Nanoeng., vol. 2, no. 16043, pp. 1-19, 2016.

[40] S. Russo, T. Ranzani, J. Gafford, C. J. Walsh, and R. J. Wood, "Soft pop-up mechanisms for micro surgical tools: Design and characterization of compliant millimeter-scale articulated structures,” Proc. - IEEE Int. Conf. Robot. Autom., vol. 2016-June, pp. 750-757, 2016. 
[41] S. Park, K. Mondal, R. M. Treadway, V. Kumar, S. Ma, J. D. Holbery, and M. D. Dickey, "Silicones for Stretchable and Durable Soft Devices: Beyond Sylgard-184,” ACS Appl. Mater. Interfaces, vol. 10, no. 13, pp. 11261-11268, 2018.

[42] B. W. An, S. Heo, S. Ji, F. Bien, and J. Park, "Transparent and flexible fingerprint sensor array with multiplexed detection of tactile pressure and skin temperature,” Nat. Commun., vol. 9, no. 2458, pp. 1-10, 2018.

[43] S. Vudayagiri, S. Zakaria, L. Yu, S. S. Hassouneh, M. Benslimane, and A. L. Skov, "High breakdown-strength composites from liquid silicone rubbers,” Smart Mater. Struct., vol. 23, no. 10, pp. 1-15, 2014.

[44] H. Silau, N. B. Stabell, F. R. Petersen, M. Pham, L. Yu, and A. L. Skov, "Weibull Analysis of Electrical Breakdown Strength as an Effective Means of Evaluating Elastomer Thin Film Quality,” vol. 1800241, pp. 1-8, 2018.

[45] J. S. Noh, "Conductive elastomers for stretchable electronics, sensors and energy harvesters," Polymers (Basel)., vol. 8, no. 4, pp. 1-19, 2016.

[46] L. Yu and A. L. Skov, "Silicone rubbers for dielectric elastomers with improved dielectric and mechanical properties as a result of substituting silica with titanium dioxide,” Int. J. Smart Nano Mater., vol. 6, no. 4, pp. 268-289, 2015.

[47] L. Yu and A. L. Skov, "ZnO as a cheap and effective filler for high breakdown strength elastomers," RSC Adv., vol. 7, no. 72, pp. 45784-45791, 2017.

[48] A. L. Skov and L. Yu, "Optimization Techniques for Improving the Performance of Silicone-Based Dielectric Elastomers,” Adv. Eng. Mater., vol. 20, no. 5, pp. 1-21, 2018.

[49] L. Yu, F. B. Madsen, and A. L. Skov, "Degradation patterns of silicone-based dielectric elastomers in electrical fields,” Int. J. Smart Nano Mater., vol. 9, no. 4, pp. 1-16, 2017.

[50] P. Sommer-larsen and A. L. Larsen, "Materials for dieletric elastomer actuators," 68 Smart Struct. Mater. 2004 Electroact. Polym. Actuators Devices (EAPAD)Proceedings SPIE, vol. 5385, pp. 68-77, 2004.

[51] T. G. Mckay, E. Calius, and I. A. Anderson, "The Dielectric Constant of 3M VHB : a Parameter in Dispute," Electroact. Polym. Actuators Devices (EAPAD)Proceedings SPIE, vol. 7287, p. 72870P:1-10, 2009.

[52] C. T. Lachowicz, "Calculation of the elastic-plastic strain energy density under cyclic and random loading," Int. J. Fatigue, vol. 23, no. 7, pp. 643-652, 2001.

[53] F. B. Madsen, S. Zakaria, L. Yu, and A. L. Skov, "Mechanical and Electrical Ageing Effects on the Long-Term Stretching of Silicone Dielectric Elastomers with Soft Fillers," Adv. Eng. Mater., vol. 18, no. 7, pp. 1154-1165, 2016.

[54] S. Zakaria, L. Yu, G. Kofod, and A. L. Skov, "The influence of static pre-stretching on the mechanical ageing of filled silicone rubbers for dielectric elastomer applications,” Mater. Today Commun., vol. 4, pp. 204-213, 2015.

[55] S. Zakaria, P. H. F. Morshuis, M. Y. Benslimane, L. Yu, and A. L. Skov, "The electrical breakdown strength of pre-stretched elastomers, with and without sample volume conservation,” Smart Mater. Struct., vol. 24, no. 5, 2015.

[56] A. Iannarelli and M. G. Niasar, "Mechanical stretch influence on lifetime of dielectric elastomer films," vol. 1016326, no. April 2017, p. 1016326, 2017.

[57] P. Lotz, M. Matysek, and H. F. Schlaak, "Lifetime of dielectric elastomer stack actuators,” no. March 2011, p. 79760P, 2011.

[58] T. Köckritz, R. Luther, G. Paschew, I. Jansen, A. Richter, O. Jost, A. Schönecker, and E. Beyer, "Full polymer dielectric elastomeric actuators (DEA) functionalised with carbon nanotubes and high-K ceramics,"

Micromachines, vol. 7, no. 10, pp. 1-15, 2016. 